\title{
EUROSON 2022, Timisoara Romania
}
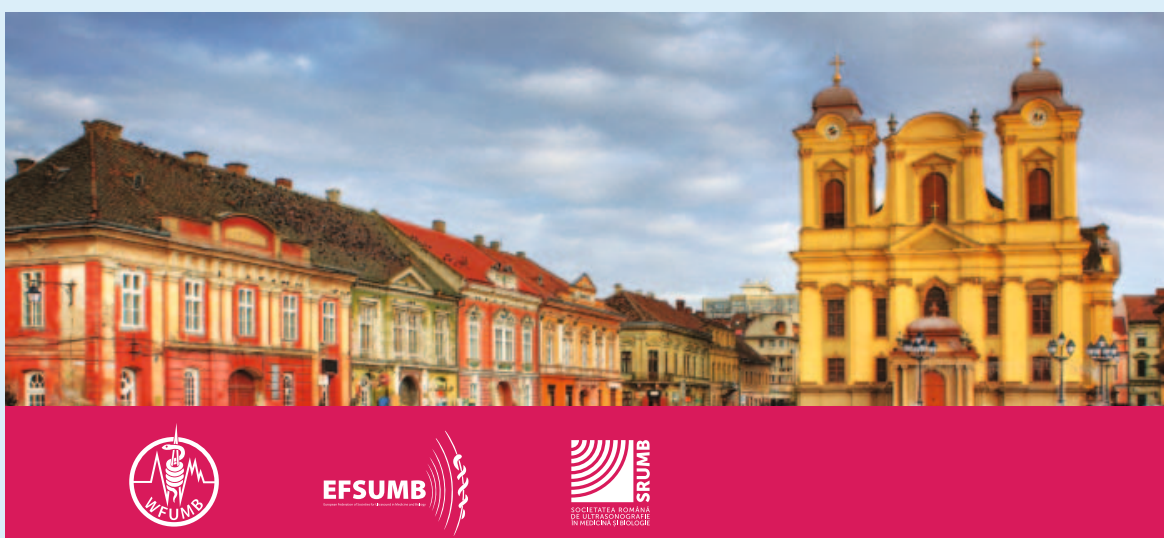

WFUMB 2022

EUROSON 2022

SRUMB 2022

The $18^{\text {th }}$ World Federation for Ultrasound in Medicine and Biology Congress WFUMB 2022

The 33 $3^{\text {rd }}$ Congress of European Federation of Societies for Ultrasound in Medicine and Biology EUROSON 2022

MAY

25-28

2022

Timișoara,

Convention

Center

The $24^{\text {th }}$ National Conference of The Romanian Society of Ultrasound in Medicine and Biology SRUMB 2022

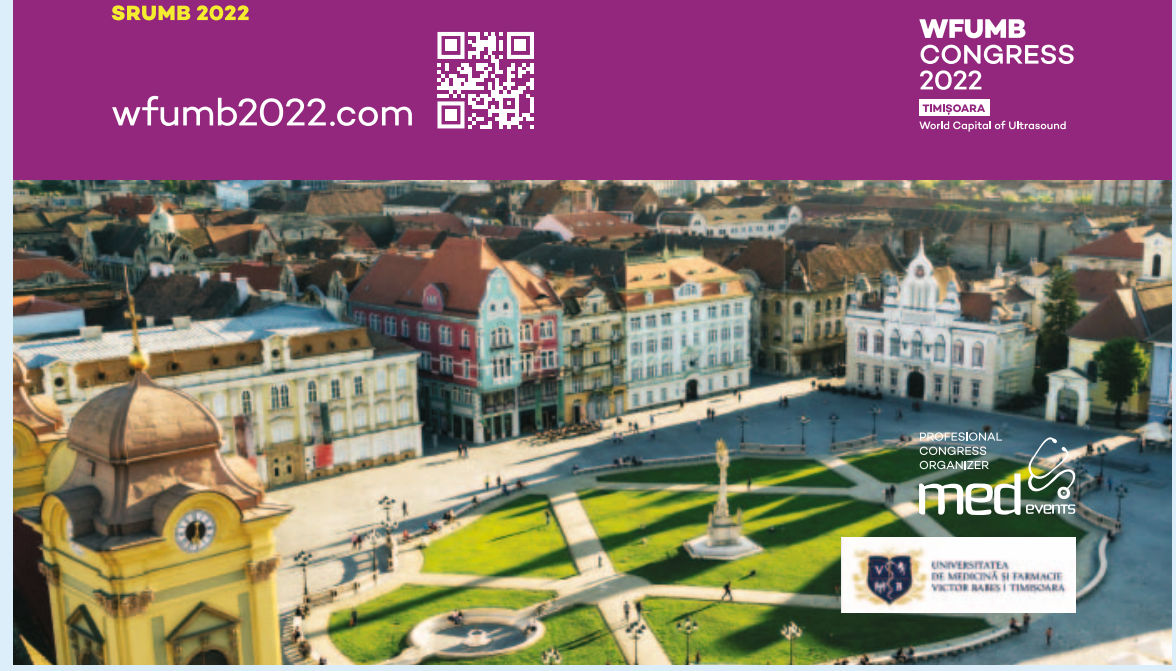

